\title{
Performance Analysis of Web Traffic Based on Visitors Behavior
}

${ }^{1}$ Azra Shireen, ${ }^{2}$ Urmila Shrawankar

${ }^{1}$ Research Scholar, Dept of Computer Sci \& Engg. G. H. Raisoni College of Engineering, Nagpur

${ }^{2}$ Associate Professor, Dept of Computer Sci \& Engg. G. H. Raisoni College of Engineering, Nagpur

Email:kamal_azra.ghrcemtechcse@raisoni.net,urmila@ieee.org

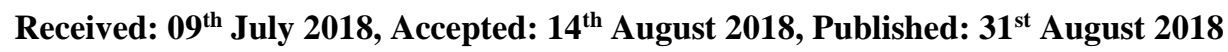

\begin{abstract}
Website plays an important role in digital marketing these days. It can also help you to increase your business's success. For making money from the website you should learn about the website visitors. The larger the number of visitors to the website is better for your business. So it is really important to learn about the visitors to analyze your website traffic. This paper contains all the details about how to create the websites for the companies and businesses and with the help of Google Analytics tool how to analyze the website visitor's traffic and their activities. By using this tool the behavior of the website can be analyze and the performance of the website can be tracked.

Different websites are created and two are checked for sample analysis. The major focus is on monitoring the behavior of the visitors like which pages they are visiting the most, at what period the visitors traffic rate is high, the version of operating system uses to visit the sites, whether the device is desktop or mobile phones etc. Online marketing is not too easy for the small businesses and companies if they don't have any idea about their real-time visitors. This project overcome the difficulties comes in analysis of small business and helps in converting the business in online marketing by introducing their market to the visitors through the websites.
\end{abstract}

Keywords: Internet, Web Visitors, Google Analytics, Digital Marketing, Optimization, WordPress.

\section{Introduction}

Now-a-days it is very common to perform online marketing rather than physical marketing. Multiple Internet users wants the product to be available online so the time of roaming from place to place will be utilized in others work. Millions of companies have their own websites which becomes the integrated part of the business's success. Many small business and companies shift from traditional services to the online services to cope up with the modernization and today's need. Websites are the primary means through which the visitors learns about the companies and interact with them. With the help of web information and data, the web designer and developer take the decision of making the website more user friendly for their online customers.

Web analytics plays an important role in collecting data and information about the Websites. Web analytics refers to the combination of measurements, collections, interpretations, analysis and presentation of information about the visitors of the websites with the aim of understanding and optimizing web experience. The main reason for using the web analytics tools is to monitor the behavior of the websites that helps in determining the web visitors and their activities like how many visitors are going through the direct references or through other social media like face book, twitter, Google Search etc. The details about the highest visiting time can help the owner to introduce the new product at that particular time so that most of the visitors learn about that product.

There are numerous web analytics tools available today which are offered by handful of companies such as Google, IBM and Mint etc. Google analytics is the most widely used analytics application which gains popularity because of its simplicity and numerous advanced features. By using this tool the site owners and marketers identify how visitors actually interact with the websites. Google analytics helps the owner of the website to track their website data and usage. With the help of Google analytics tool the owner gets the knowledge of real-time audience and their visiting pages, the bounce rate, exit rate, new users as well as existing users can also be analyze with an ease. It also gives the knowledge about the devices like its operating system versions, screen resolution, browser etc. Google analytics does not require any kind of software installation; it stores all its data on Google's own server.

\section{Literature Review}

The Internet is playing the major role from the past 17 years in digital marketing. In 1991 the concept of Ecommerce was introduces and thousands of businesses have taken up residences at websites [3]. In 2000 a great number of businesses from all over the world represented their services in the websites [3]. Nearly all businesses and companies now have 
a website which enriches the image of business and provides them direct and indirect benefits like ecommerce sales, information, services etc [2].

The below figure defines of total numbers of users using Internet worldwide from the year 2005 to 2017[10].

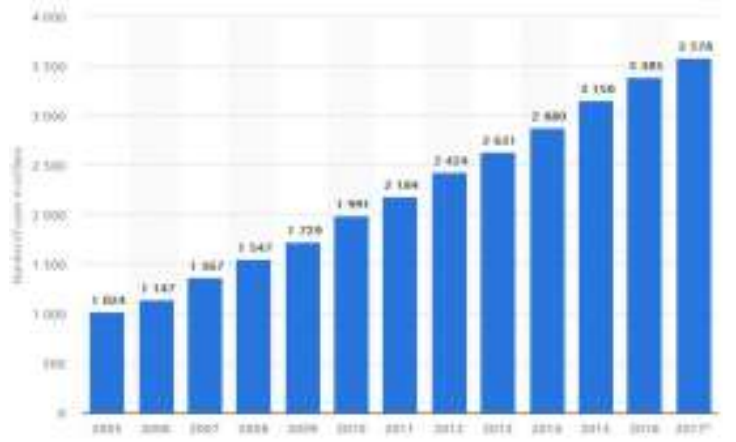

Figure 1. Total Numbers of Internet users Worldwide from 2005 to 2017

The below Figure defines the Percentage of the population accessing the Internet globally from the year 2005 to 2017, by using their marketing skills and maturity [11].

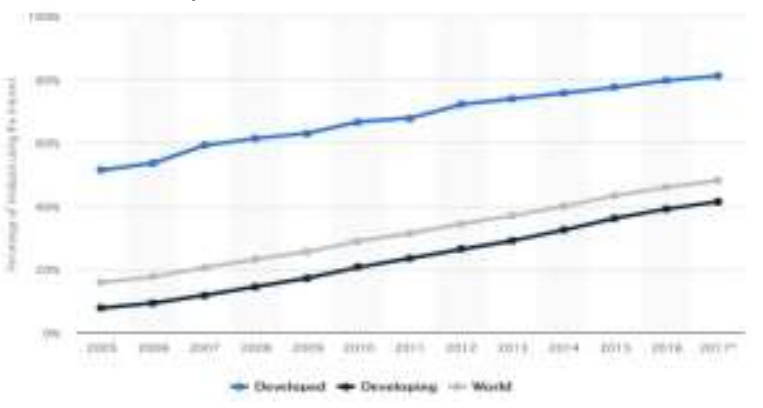

Figure 2. Percentage of Global Population Accessing the Internet from 2005 to 2017

The figure below defines the use of mobile phones for gaining website traffic from 2009 to 2017[5].

In 2009, the percentage of web traffic worldwide which was generated using mobile phones was only $0.7 \%$, the reason may be less availability of Internet connection and the lack of mobile-friendly web sites but in 2017 the rate is $50.3 \%$ which indicates the growth of website visitor traffic [5].

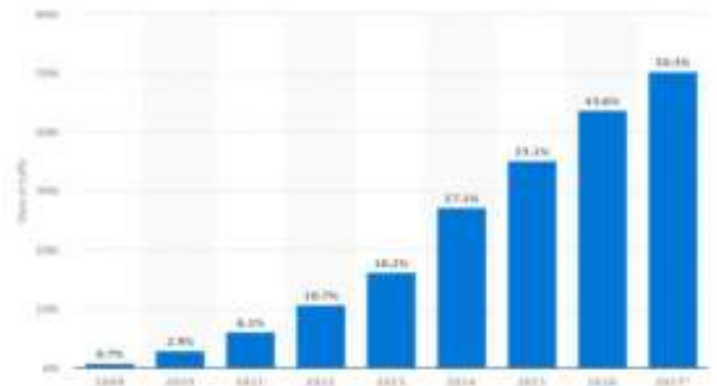

Figure 3. Mobile Phones uses for Website Traffic from 2009 to 2017

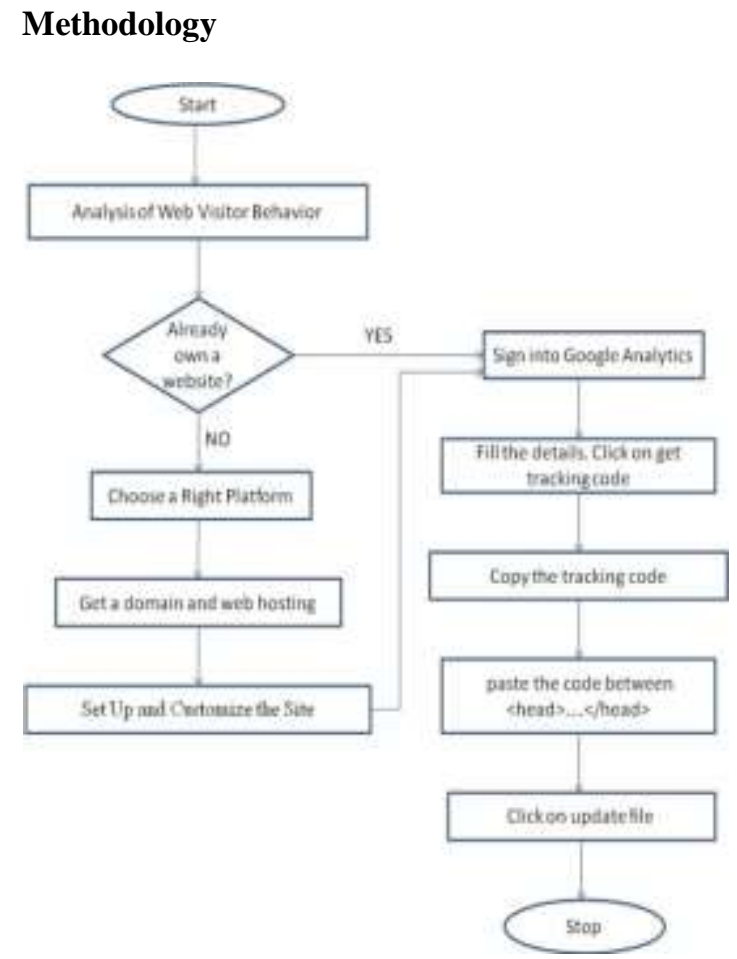

Figure 4. Flowchart of Project

\section{Creating Website}

Step 1: Choose a right Platform

There are multiple ways to build websites using technical languages such as HTML, CSS and Flash which takes a lot of time and patience to learn, understand and really tricky to master. This is the reason most people afraid of creating website from scratch. The WordPress have made the creation of a website easy and accessible to everyone.

Step2: Get a domain and web hosting plan

There are multiple web hosting companies which are paid like bluehost, Go Daddy which provides the domain name and various hosting plans. For free domain and web hosting plan use freenom and infinityfree.net.

\section{Go to Freenom:}

Check the availability of your domain name. Select the extension according to your choice and click on sign out.

\section{Go to Infinityfree.net:}

Create an account and select the hosting plan which is freely available for a year and register your domain name

Step 3:Set Up and Customize the Site

Now install your wordpress from Infinityfree.net c panel.

1. Login to the control panel 
Helix Vol. 8(5): 3879- 3883

2. Select Softaculous Apps Installer

4. Click on WordPress

5. Click on install now

Step 4: Build the website

According to the business and company profile customize the website.

Install Google analytics to the Website:

Google analytics setup can be installed by using plugins and manually.

1. Install Plugins In Wordpress Website:

Open the admin page and install monster insight plugins to start the google analytics. It will automatically generate the tracking code.

2. Install Google analytics manually:

Step1: Create an google account and sign up to www.google/analytics.com.

Step2: Fill the details of your website and click on get tracking code

Step3: Go to the Wordpress dashboard and clicks on customize and select editor. In editor open the header html code.

Step4: Copy the tracking code from Google analytics and paste the code between $\langle$ head $>$... $<$ /head $>$. Click on update file.

\section{Components of Google Analytics:}

The owner and developer of the website interact and influence through a user interface and APIs that are organized into four main components-

\section{Collection:}

Google analytics depends on collection of data to generate reports. It allows collecting user interaction data.

\section{Configuration:}

Configuration setting in properties and views allow taking full control of how the data will be transformed or processed.

\section{Processing:}

It allows managing how the data is processed in Google analytics.

\section{Reporting:}

Google analytics reporting interface use to call any kind of information and data that require for reporting and analysis.

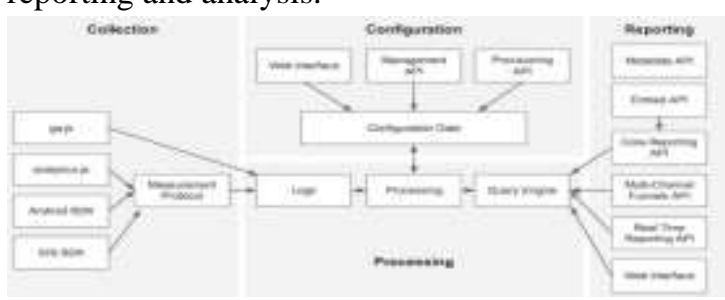

Figure 5. Components of Google Analytics

\section{Results and Analysis}

Two different websites are built to perform analytics.

1. http://kamalstoreworld.cf

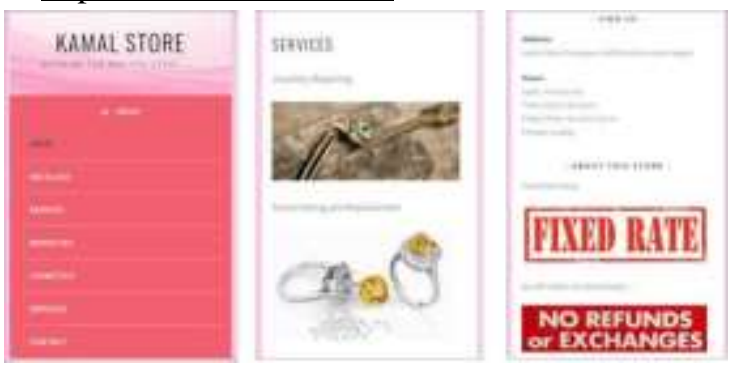

This is the commercial website used for the purpose of marketing and analyzing the behavior of the visitors. This website include all the details of jewelry and cosmetic available at that shop.

\section{2. http://urmilashrawankar.ml}

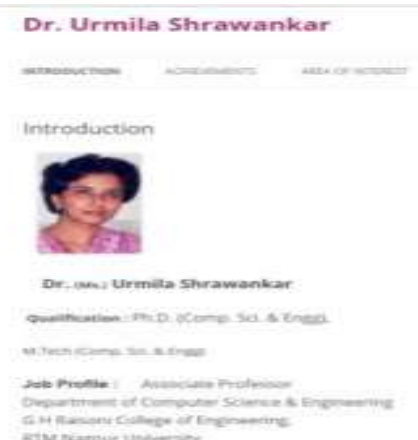

This is the educational website that contains the details of the publications, patent filed etc of a scholar that helps student in their academics.

\section{Audience Overview}

The audience overview report of these two websites defines the interested visitors of the websites. It shows all the details about the users like whether the user is new or existing one, how much time they spend on website, which pages of website they like most, exit rate and bounce rate, devices they used, operating system version, screen resolution, countries etc

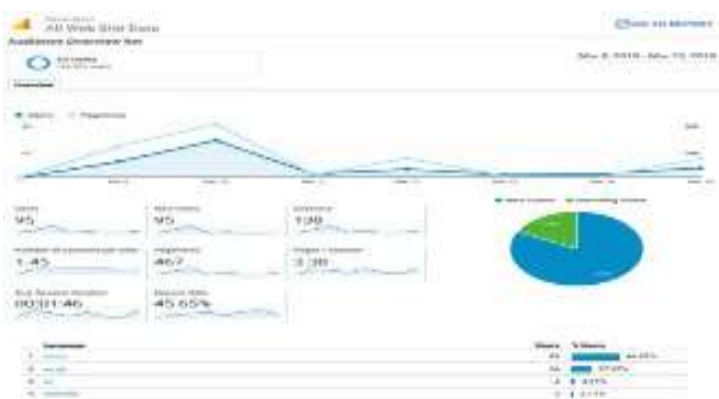

Figure 6. Audience Overview Report of http://kamalstoreworld.cf 
The graph defines the ratio of user and page views. The blue colour in the bar defines the percentage new visitors and green colour defines the percentage of returning visitors.

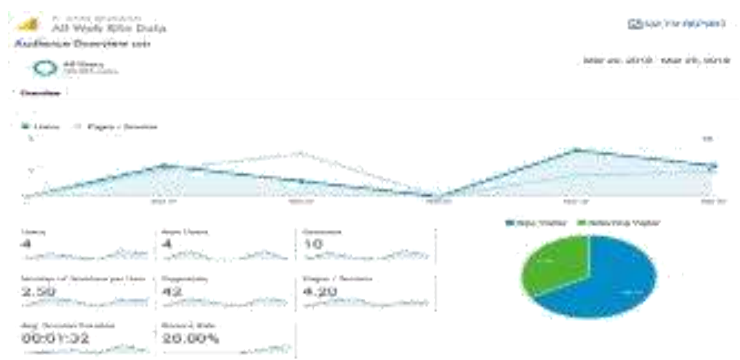

Figure 7. Audience Overview Repert of http://urmilashrawankar.ml

The graph defines the ratio of user and page views. The green colour in the bar defines the percentage of new visitors and blue colour defines the percentage of returning visitors.

\section{Active Users:}

The active user report defines the real time user in the website. It also defines the user according to the weeks and months.

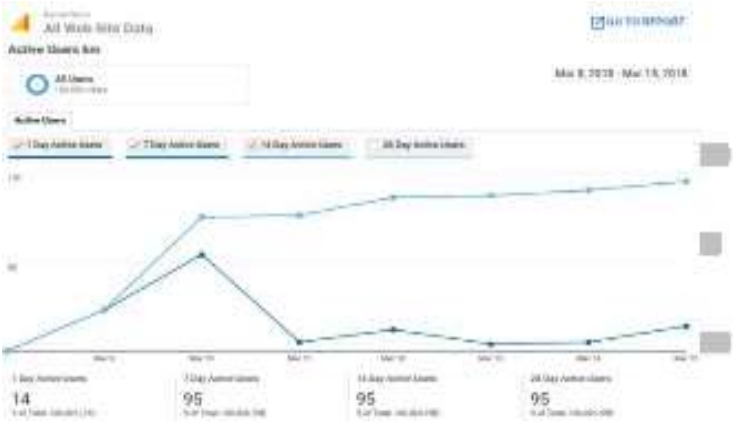

Figure 8. Active User Report of http://kamalstoreworld.cf

The figure defines the growth of user in a very limited time. The graph are defines in the shades of four colour so that the representation of the particular days or weeks can be highlight and provide a clear vision.

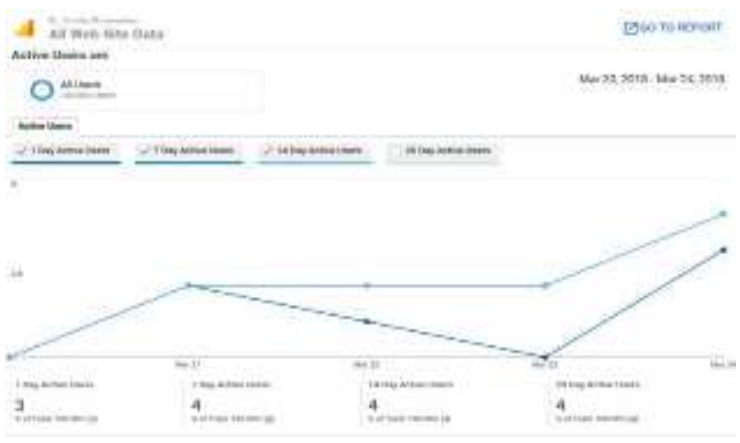

Figure 9. Active User Report of http://urmilashrawankar.ml
Figure defines that the user are increasing slowly as compare to the commercial website. Mostly the traffic rate of educational websites increased in the period of examination.

\section{Device Overview Report:}

The device overview report defines the types of devices used to visit the websites. It defines whether the visitor uses mobile phones or desktop. It also indicates the developer that the total number of mobile user now exceeds the total number of desktop users.

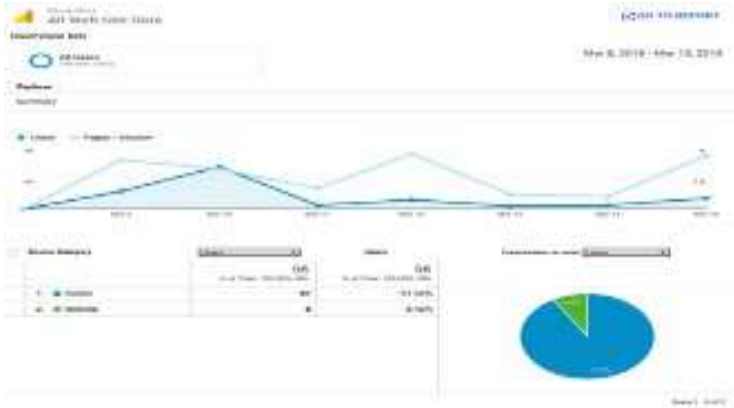

Figure 10. Device Overview Report of http://kamalstoreworld.cf

The graph defines the ratio of user and pages/sessions. The green colour in the bar graph defines the percentage of desktop users and blue colour defines the percentage of mobile users.

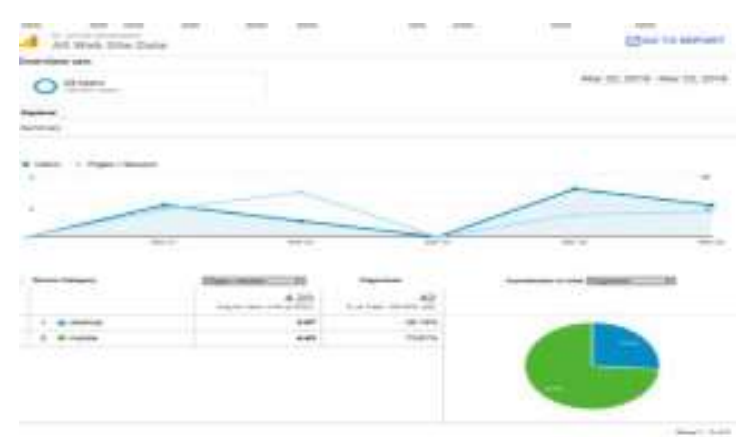

Figure 11. Device Overview Report of http://urmilashrawankar.ml

The graph defines the ratio of user and pages/sessions. The blue colour in the bar graph defines the percentage of desktop users and green colour defines the percentage of mobile users.

\section{Conclusion}

This paper contains all the details require to analyze the web visitor behavior by using Google analytics tool. By using this tool the owner gets the details of the visitors that help the owner to make the revenue online. Today's era is considered as a world of technology and digitalization. For the growth and development of companies and businesses the 
Helix Vol. 8(5): 3879- 3883

knowledge about the web analytics is necessary. In the paper, the main objective is to monitoring the behavior of the visitors on the website. By using Google Analytics I conclude that it is an efficient tool for calculating and analyzing the visitors behavior. All the details of the website can be analyzed and the profits can be increased. The analysis defines the new way to develop your business and help in making it user friendly.

\section{Future Scope}

Analyzing web visitors behaviour plays an important role in the field of digital marketing and search engine optimization. By analyzing the traffic of the website the developer get the idea of providing the valuable pages to the visitors. In Future all the interaction would likely to perform on the websites like transaction, meetings, marketing etc. Also the previous research in web analytics is concentrated on data and web metrics. It is important to remember that there are also other ways to collect data about websites and their visitors. The location of the individual behavior help in contacting them through emails that proves helpful for the growth of online sales.

\section{References}

1. Mr. Pratik V. Pande, Mr. N.M. Tarbani, Mr. Pavan V. Ingalkar "A Study of Web Traffic Analysis", Pratik V. Pande et al, International Journal of Computer Science and Mobile Computing, Vol.3 Issue.3, March- 2014, pg. 900907

2. Deepika Verma, Depanwita Seal, Atul Pandey "Google Analytics for Robust Website Analytics"

3. Mohammad Amin Omidvar, Vahid Reza Mirabi And Narjes Shokry "Analyzing The Impact Of Visitors On Page Views With Google Analytics" International Journal of Web \& Semantic Technology (IJWesT) Vol.2, No.1, January 2011.

4. Clifton, B. (2012). Advanced web metrics with Google Analytics (3rd ed.). Indianapolis, IN: John Wiley \& Sons.

5. https://www.smartinsights.com/searchengine-marketing/search-engine-statistics/

6. Ultimate Guide: How to Make a Website http://www.wpbeginner.com/guides/

7. How to install Wordpress https://infinityfree.net/support/how-to-installwordpress/

8. How to Install Google Analytics in WordPress for Begin "http://www.wpbeginner.com/beginners- guide/how-to-install-google-analyticswordpress/

9. Himani Singal, Shruti Kohli, Amit Kumar Sharma "web analytics: state-of-art \&literature assessment"@2014 ieee.

10. Suchita Rawool, Amit Boke, Geocy Shejy "Gaining Advantages using Web Analytics:A case study on Ryanair", 2015 IJEDR | Volume 3, Issue 2| ISSN: 2321-9939.

11. Number of internet users worldwide from 2005 to 2017 https://www.statista.com/statistics/273018/numb er-of-internet-users-worldwide/

12. "https://www.statista.com/statistics/20909 6/shar e-of-internet-users-in-the-total-worldpopulation-since-2006/"' 